\title{
As incubadoras sociais do Rio Grande do Sul na base de fomento da práxis emancipatória: algumas problematizações
}

\author{
Rio Grande do Sul social incubators on the promoting basis of emancipatory \\ praxis: some problematizations

\section{Les incubateurs sociaux de Rio Grande do Sul fondent sur la promotion de la praxie émancipatoire: quelques problématisations}

\section{Las incubadoras sociales del Rio Grande do Sul en la base de fomento de la práctica emancipatoria: algunas problematizaciones}

\author{
Fabio Jardel Gaviraghi ${ }^{1}$ \\ Caroline Goerck ${ }^{1}$ \\ Walter Frantz ${ }^{2}$ \\ Recebido em 06/02/2018; revisado e aprovado em 02/04/2018; aceito em 13/04/2018 \\ DOI: http://dx.doi.org/10.20435/inter.v0i0.1834
}

\begin{abstract}
Resumo: Este artigo problematiza resultados de uma pesquisa de doutorado, realizada em 2016, que tinha por objetivo analisar como as incubadoras sociais universitárias estão desenvolvendo o processo de incubação com os empreendimentos de geração de trabalho e renda, buscando averiguar se tal acontece nas perspectivas da educação popular e no enfrentamento das refrações da questão social. Os resultados mostram que as Incubadoras estão promovendo ações de formação emancipatória, pois utilizam-se da educação popular e contribuem com o desenvolvimento local.
\end{abstract}

Palavras-chave: universidade; extensão universitária; incubadoras sociais, formação emancipatória.

Abstract: The article problematizes results of the research that had as objective to analyze how the university incubators are developing the process of incubation with the enterprises of generation of work and income, trying to find out if it happens in the perspectives of the popular education and in the confrontation of the refractions of the social question. The results show that the Incubators are promoting actions of emancipatory formation, observing popular education and promoting local development.

Keywords: university; university extension; social incubators; emancipatory formation.

Résumé: L'article problématise les résultats de la recherche qui avait pour objectif d'analyser comment les incubateurs universitaires développent le processus d'incubation avec les entreprises de génération de travail et de revenu, essayant de savoir si cela se passe dans les perspectives de l'éducation populaire et la confrontation des réfractions de la question sociale. Les résultats montrent que les Incubateurs promeuvent des actions de formation émancipatrice, observent l'éducation populaire et favorisent le développement local. Mots-clés: université; extension de l'université; incubateurs sociaux; formation émancipatrice.

Resumen: El artículo problematiza resultados de la investigación que tenía por objetivo analizar cómo las incubadoras sociales universitarias están desarrollando el proceso de incubación con los emprendimientos de generación de trabajo y renta, buscando averiguar si ocurre en las perspectivas de la educación popular y en el enfrentamiento de las refracciones de la cuestión social. Los resultados muestran que las Incubadoras están promoviendo acciones de formación emancipatoria, observando educación popular y promoviendo el desarrollo local.

Palabras clave: universidad; extensión universitária; incubadoras sociales; formación emancipatória.

\footnotetext{
${ }^{1}$ Universidade Federal de Santa Maria (UFSM), Santa Maria, Rio Grande do Sul, Brasil.

2 Universidade Regional do Noroeste do Estado do Rio Grande do Sul (UNIJUÍ), ljuí, Rio Grande do Sul, Brasil.
} 


\section{INTRODUÇÃO}

O presente artigo visa apresentar parte dos resultados de uma pesquisa ${ }^{3}$ de doutoramento, agregada de problematizações elencadas por autores integrantes de debates sobre a temática. Tal pesquisa buscou problematizar e analisar a inserção das Incubadoras Sociais Universitárias (ISUs) no leque de possibilidades de fomento aos trabalhadores exclusos do mercado formal de trabalho e que estão inseridos em grupos de geração de renda com características autogestionárias e cooperadas. Esses empreendimentos de economia solidária (EES) estão constituindo-se como uma das possíveis formas de resistência e enfrentamento à exclusão social que se agravou na sociedade contemporânea, regida pelo ideário neoliberal.

Ao realizar o trabalho de assessoria, formação e/ou qualificação dos empreendimentos de economia solidária, as ISUs apresentam-se como uma das possíveis alternativas para formar e consolidar as iniciativas de economia solidária (ES) no Brasil. Busca-se, dessa maneira, promover, ao longo das práticas da incubação, a construção de conhecimentos, por meio de um processo prático educativo, que objetiva organizar e acompanhar de forma sistemática grupos e trabalhadores interessados em formar os empreendimentos de ES (CULTI, 2009). Devido à possibilidade de construção de novos conhecimentos; à articulação dos saberes técnico-científicos e populares; e à qualificação dos saberes já existentes, as incubadoras buscam contribuir para a efetivação da função social das universidades e para a redução da distância entre universidade e sociedade.

As universidades, mediante as atividades do tripé ensino, pesquisa e extensão, estão implicadas a prestar serviços para a comunidade na qual estão inseridas, especialmente, por meio da extensão universitária. A prática da extensão como oportunidade de promover a práxis do conhecimento acadêmico, em alguns casos, conta com as ISUs, as quais reúnem professores, pesquisadores, técnicos em assuntos educacionais e acadêmicos das mais diversas áreas do conhecimento e que possuem interesse e/ou disponibilidade em desenvolver ações de incubação. Essas ações e práticas objetivam a formação dos EES, por intermédio da assessoria contínua, a fim de problematizar os princípios do cooperativismo, contribuir para a organização e qualificação das atividades produtivas, bem como para a prestação de serviços de apoio e a legalização das associações e cooperativas incubadas (INSTITUTO DE TECNOLOGIA SOCIAL [ITS], 2010).

Nessa perspectiva, tem-se o entendimento de que os grupos isolados ainda não possuem condições para superar a estrutura capitalista de forma individualizada. Parte-se, entretanto, do pressuposto de que, fortalecidos, ampliam as possibilidades de trabalho e renda para manter esses sujeitos em condições de luta para ampliação dos direitos sociais e acesso a eles, incluindo a luta por uma condição socioeconômica que lhes permita inclusão social não perversa, isto é, que respeite os direitos humanos, sociais, econômicos e culturais dos sujeitos.

Entende-se, desse modo, que uma nova condição socioeconômica poderá ser germinada nesses espaços, quando ocorrer o fomento e a viabilização de uma formação que siga, em especial, os princípios da educação popular com características emancipatórias, constituindo, assim, as práticas educativas um campo de produção de novos conhecimentos e de valorização dos saberes populares. Essa concepção pedagógica e prática social buscam contribuir para a constituição dos trabalhadores, no caso das incubadoras, como sujeitos de seu próprio processo de transformação, promovendo empoderamento, alternativas para a emancipação social, superação dos processos de alienação e uma porta de saída da pobreza.

\footnotetext{
${ }^{3}$ Durante o Doutorado, foi realizado o estágio sanduíche na Universidade de Coimbra, com Bolsa Capes.
} 
As ISUs como instituições apoiadoras da organização de iniciativas de economia solidária são, muitas vezes, a única possibilidade para alguns grupos sociais ameaçados de exclusão. Como tais, são permeadas por desafios oriundos da organização societária, que tem valorado, em especial, os princípios dos ditames do capital, da globalização econômica e do ideário neoliberal e, talvez, da supervalorização do conhecimento científico. Diante disso, na sequência, serão apresentados os aspectos metodológicos da pesquisa, algumas reflexões teóricas, bem como, análises que dão visibilidade à temática proposta.

\section{ASPECTOS METODOLÓGICOS}

A pesquisa, base de discussão desta pesquisa, teve como problema central verificar como as incubadoras sociais universitárias, mediante o processo de incubação, projetam e/ ou significam a perspectiva da educação popular na formação dos atores envolvidos e no enfrentamento às manifestações da questão social no Rio Grande do Sul. A pesquisa seguiu os preceitos qualitativos e foi realizada com quatro incubadoras sociais universitárias e os respectivos EES incubados, todos localizados no estado do Rio Grande do Sul. Além disso, o estudo seguiu o método dialético crítico, por entender que este permite uma melhor análise da sociedade, e foi utilizada para a análise dos dados a técnica de análise de conteúdo, baseada em Bardin (2011).

Segundo Minayo (2013), a abordagem qualitativa possibilita o aprofundamento dos significados das ações e relações humanas, sendo geralmente imperceptível e quase impossível de ser captado por meio de adequações, medidas e estatísticas. O referencial teórico-metodológico utilizado é o método dialético-crítico, com o aporte na teoria social crítica com base em Marx e Engels, que possibilita a leitura da realidade e a concepção sobre o homem e o mundo de forma que se apreenda o real, analisando e percebendo também a base material que o constitui (GADOTTI, 2012).

Anteriormente à pesquisa de campo, no caso, a busca de dados junto às pessoas, realizou-se um resgate dos materiais já produzidos ou pesquisados sobre a temática. Na sequência, foi realizada a busca dos dados empíricos, INICIANDO-se por meio de contato telefônico e via e-mail, para posteriormente ser realizada a visita in loco nas ISUs e nos respectivos empreendimentos incubados.

\section{AS UNIVERSIDADES E SUAS ACEPÇÕES PARA A TRANSFORMAÇÃO SOCIAL}

As universidades possuem papel central na organização da sociedade contemporânea, especialmente por serem um espaço privilegiado de produção e disseminação de conhecimento, o qual, em tese, tem por objetivo contribuir para a existência de uma sociedade que preconize o desenvolvimento socioeconômico justo e igualitário. Para tanto, desde a Constituição Federal de 1988, há, entre seus princípios ${ }^{4}$, a indissociabilidade entre o ensino, a pesquisa e a extensão (FRANTZ, 2010), tripé da promoção da educação superior. Esta, segundo a Lei de Diretrizes e Bases (LDB), Lei n. 9.394, em seu artigo 43, item IV, visa "estimular o conhecimento dos problemas do mundo presente, em particular as nacionais e regionais, prestar serviços especializados à comunidade e estabelecer com esta uma relação de reciprocidade" (BRASIL, 1996).

\footnotetext{
${ }^{4}$ Artigo 207 da Constituição Federal de 1988.
} 
Ademais, Frantz (2013, p. 18-23) declara que a universidade "é um produto da ação e da reflexão humana, um espaço de poder, exercidas pelas mais diversas formas, por meio das mais diversas áreas e campos de saberes", sendo um lugar de "afirmação do diálogo, da argumentação, do debate entre os seres humanos, no campo das ideias [...] tendo por denominador comum a liberdade". O autor segue ainda afirmando que a universidade não pode ser neutra e precisa agir/fazer "como lugar de conhecimento em favor da vida, a questão suprema de nossa existência”" (FRANTZ, 2013, p. 17).

Nessa perspectiva, as universidades são consideradas espaços contraditórios e conflitantes, porém, mesmo assim, com a extensão universitária, tem adquirido significativa importância como espaço de contestação. Isso ocorre em função de que, após o ano 2000, a extensão tem levado conhecimento científico para fora dos muros da universidade e se retroalimentado dos conhecimentos que estão presentes nas comunidades populares, o que desafia docentes, técnicos em assuntos educacionais e discentes a compreender e potencializar as ações lá pensadas, projetadas e executadas.

A extensão universitária, para Santos (2016, p. 74), consiste em uma vasta área de prestação de serviços para os mais variados destinatários, em especial aos movimentos sociais, às comunidades regionais e locais, aos grupos sociais e populares e suas organizações, aos governos e outras instituições públicas e privadas. Entre as ações que são desenvolvidas estão "incubação da inovação, promoção da cultura científica e técnica, atividades culturais no domínio das artes e da cultura", visando sempre à articulação do tripé com a comunidade na qual está inserido. O autor menciona ainda que a extensão deve ter por objetivo prioritário o apoio na resolução dos problemas da exclusão e das discriminações sociais, dando voz aos excluídos e discriminados.

As ações extensionistas têm desempenhado o seu papel por meio do diálogo, da comunicação de modo a promover a formação humana de cunho emancipatório, tanto do público-alvo, como dos próprios agentes internos das universidades. A formação humana, segundo Barcelos (2010, p. 173), " [...] está na constituição da essencialidade da função das universidades enquanto instituições educativas, abertas às muitas possibilidades de construção de conhecimento que qualifica a vida das pessoas e dos processos sociais", mesmo que enfrente desafios cotidianos para desenvolver os seus preceitos.

A busca por qualificação da vida das pessoas acontece, segundo Nogueira (2005, p. 85), na relação de reciprocidade entre universidade e comunidade, na priorização de metodologias participativas e que favoreçam o diálogo entre pesquisadores e pesquisados, "visando a criação e recriação de conhecimentos possibilitadores de transformações sociais, onde a questão central será identificar o que deve ser pesquisado e para quais fins e interesses se buscam novos conhecimentos".

As ISUs, nesse contexto, podem servir de modelo de ação das universidades no combate ao desemprego e à exclusão social, principais expoentes da questão social. Santos e Cruz (2008) afirmam que essas organizações, as ISUs, podem se apresentar e se constituir como um dos caminhos para recolocar as universidades no âmbito das lutas sociais, justamente por possuírem compromisso com o mundo do trabalho. Podem, assim, promover também a formação humana com perspectivas críticas, de educação popular e emancipatória, ampliando momentos de questionamentos, de investigação da realidade existente e os caminhos que podem ser seguidos. 


\section{O PROCESSO DE INCUBAÇÃO: CARACTERÍSTICAS INICIAIS, CAMINHOS/CONCEITOS JÁ CONSTRUÍDOS E A QUESTÃO DA FORMAÇÃO EMANCIPATÓRIA}

Os EEES são organizados a partir da necessidade de propor e criar alternativas de geração de trabalho e renda em um sistema regido pelo capital. Esses empreendimentos são uma condição, uma imposição ou uma saída ao desemprego, para muitos, porém carecem de apoio continuado, fomento financeiro e/ou pesquisas que identifiquem suas principais limitações e os caminhos a serem percorridos para atingir e/ou manter a viabilidade socioeconômica.

A incubação aos EESs tornou-se possível a partir do momento em que alguns setores das universidades brasileiras, em especial no início da década de 1990, questionaram se as ações que estavam sendo desenvolvidas tinham por objetivo reverter o quadro de miséria das populações pobres brasileiras (SANTOS; CRUZ, 2008). Como resultado desse processo de questionamento interno, além da demanda já apresentada por parte dos empreendimentos, teve-se o surgimento de ideias e experiências que foram basilares para a criação das ISUs, as quais inicialmente se constituíam como pequenos projetos de extensão com reduzidas atividades.

Fraga (2012, p. 19) entende que as ISUs são constituídas por grupos de professores, estudantes, servidores que atuam junto a grupos populares (cooperativas/associações/grupos informais) "com intuito de assessorá-los em suas atividades de produção, comercialização e de organização política". Observa-se a necessidade de integração entre os segmentos de recursos humanos estruturantes da universidade, os quais desenvolvem o processo de incubação mediante reuniões, palestras, oficinas, encaminhamentos para políticas públicas, atividades de formação, atividades de planejamento e avaliação, entre outras ações, que, de forma articulada, propositiva e formativa, vão fomentando os EES.

Para Coimbra e Souza (2007, p. 2-6), as ISUs foram instituídas "como uma resposta da universidade brasileira aos problemas sociais relacionados ao trabalho". Os autores que essas ISUs possuem como objetivo "organizarem-se para oferecer suporte à formação e ao desenvolvimento de experiências de geração de trabalho e renda, sob a forma de coletivos de trabalhadores em situação de desemprego, com vínculos precários ou em vulnerabilidade social”, mas que buscam acessar um trabalho baseado em outras relações, não o de subordinação, vinculados à economia solidária.

Eid (2004, p. 167) acredita, entretanto, que não existem fórmulas prontas, pois os métodos são possibilidades, caminhos ou sugestões para o desenvolvimento das atividades. $\mathrm{O}$ autor pontua a importância- apesar de sua complexidade- da interdisciplinaridade, nesse processo, ser transformada em transdisciplinaridade, a fim de possibilitar uma educação unitária, superando a "fragmentação do conhecimento por via de um processo interativo entre os agentes educadores e educandos".

Esse enfrentamento da fragmentação do conhecimento, que busca uma educação unitária e, ao mesmo tempo, crítica e propositiva, tem ocorrido nas ISUs. Porém é necessário considerar que é apenas um tímido processo, sendo necessário ampliar o trabalho socioeducativo, envolvendo e aproximando as diversas áreas de conhecimento, os gestores das instituições de ensino superior e os grupos que estão sendo incubados para que se efetive, dessa forma, uma formação com propósitos emancipatórios.

A metodologia de incubação, para Eid (2004), concentra as práticas em duas perspectivas. A primeira perspectiva seria a do debate teórico, que busca a relação entre capital e trabalho, 
promovendo discussões que têm como foco a construção de uma alternativa para a emancipação social por meio da economia solidária. A segunda, por sua vez, seria quando as ISUs desenvolvem suas práticas de forma pragmática, promovendo simplesmente assessoramento técnico para inserir os produtos e serviços dos grupos no mercado, com foco apenas na geração de renda.

A primeira etapa da incubação consiste na pré-incubação. Para Moura (2014), essa fase corresponde ao processo de sensibilização e diagnóstico que objetive a aproximação das ISUS com os empreendimentos. Esse é o período de estudo de viabilidade do grupo, no qual se estabelece um plano de trabalho, com metas e um processo de diálogo entre empreendimentos e equipe de incubação, ou seja, consiste na aproximação inicial com os grupos, quando associados/ cooperados realizam a solicitação de incubação (EID, 2004).

A incubação, por sua vez, acontece também por meio de um planejamento participativo que define as ações a serem realizadas no processo de assessoria/consultoria/acompanhamento dos grupos. Nesse momento, são realizadas reuniões com profissionais das diversas áreas envolvidas diretamente ou de forma complementar à incubação. Na sequência, desenvolvem-se as demais qualificações, as quais envolvem as questões administrativas e contábeis, bem como outras oriundas dos empreendimentos (EID, 2004).

A pós-incubação, para Eid (2004), é a etapa em que se realizam ações pontuais, de aconselhamento, de proposições e de decisões estratégicas para a viabilidade dos empreendimentos. Esse período é de extrema dificuldade, pois, em função da dura realidade que esses grupos enfrentam, a incubação, por si só, pode não conseguir gerar sua viabilidade e/ou sustentabilidade.

Observa-se, assim, que a universidade, em seu papel, leva ou procura levar para além dos muros da universidade o seu conhecimento acumulado, porém "não é possível falar em 'transmissão de conhecimentos', como algo que se dá a alguém 'que não sabe', e sim uma 'partilha de conhecimentos, que pressupõe uma troca'". A universidade também deve ir buscar conhecimento nessa interação com os empreendimentos, na qual as soluções para o cotidiano dos grupos podem não vir do conhecimento construído dentro das universidades (CULTI, 2010).

A educação precisa estar voltada para a emancipação. É necessário destacar a compreensão de que a educação e a formação de caráter emancipatória contribuem para o processo de transformação social. A educação na perspectiva emancipatória refere-se à concepção, ao ideal, à teoria, à ética e à perspectiva. Para promover esse processo de transformação social, tendo as ISUs como caminho - em que os agentes centrais são os trabalhadores - a perspectiva para a educação e o trabalho "deve desenvolver a capacidade de pensar criticamente a realidade e promover a justiça e a solidariedade fundada na ética, e respeitando a dignidade e a autonomia do educando", como aponta Gadotti (2012, p. 2).

Passa a ser um papel das ISUs, como entende Culti (2007, p. 21), possibilitar outra "forma de ver o mundo, [...] a valorizar e estimular mais o diálogo, a participação e a autocrítica enquanto educadores e pessoas", ou seja, possibilitar um processo de formação interna com propósitos de construção coletiva de conhecimento. Para Gadotti (2012, p. 2), quanto à formação na perspectiva emancipatória, "importa que a práxis educativa construa sujeitos autônomos, pensantes, sujeitos capazes de autogovernar-se e de governar".

De acordo com Oliveira (2014, p. 28), o processo de incubação:

[...] se mostra um espaço possível, necessário e alternativo para uma educação sóciodialógica, onde as trocas se fundam a partir de um território local e da comunidade, dos laços sociais mais profundos e verdadeiros. Educação sócio-dialógica para o trabalho cooperado/ 
associado/solidário/empreendedor que seria: ênfase no trabalho artífice, fazer bem feito com os outros, "concertar" as relações sociais, ou seja, ressignificar o estar junto, gerenciar conflitos e interesses, atentar e valorizar o indivíduo, mas estimular os resultados para o bem coletivo, resgatar e estimular o prazer de viver em comunidade, reforçar a cooperação forte através dos hábitos, ritos e culturas que superam o narcisismo e egocentrismo da sociedade atual.

O saber puramente utilitário e desproblematizado ocorre quando "a educação se reduz à transferência de receitas, de pacotes conteudísticos [...]". Na perspectiva dialética e não determinista, por outro lado, a educação é cada vez mais uma "experiência de decisão, de ruptura, de pensar certo, de conhecimento crítico" (FREIRE, 2015, p. 179).

Não existe uma única definição para a educação popular, já que esta se expressa por meio de algumas práticas de educação emancipadora, pois é "um movimento prático e teórico em educação, presente em processos de organização das classes trabalhadoras, sobretudo nos que apresentam profunda crítica à educação dominante" (MELO NETO, 2011, p. 32), promovendo características emancipatórias ou integrando-se a elas.

A educação popular, como campo de conhecimento e prática educativa, vem se constituindo como um exercício permanente de crítica ao sistema societário vigente, que é de "contra-hegemonia ao padrão de sociabilidade por ele difundida". Desse modo, foi construída, na América Latina, nos processos de luta e resistência das classes populares, sendo formulada e vivida como "uma concepção educativa que vincula explicitamente a educação e a política, na busca de contribuir para a construção de processos de resistência e emancipação humana", requerendo sempre uma sociedade que não seja regida pelo capital (PALUDO, 2015, p. 220).

Santos (2016) defende que as universidades precisam e têm a possibilidade de reforçar essa essência, de assumir uma atitude anticapitalista. É necessário também que a educação popular se alie à universidade para descolonizar a educação, trazendo para a sala de aula a luta, essencial para conhecer o mundo. Esse é um caminho a ser seguido, respeitando o diálogo entre os conhecimentos e entre os atores envolvidos nas incubadoras.

A educação popular, quando utilizada, reportando-se às ações de incubação, permite que os associados dos EES possam desvelar a realidade. Como aponta Torres (2013), aprender a ler a realidade possibilita que os educadores e educandos escrevam a sua própria realidade, pois passam a compreender, de forma crítica, o seu mundo, atuando na busca da sua transformação e da superação dos processos de alienação, por exemplo. Dessa forma, utilizando-se dos conhecimentos ou da sabedoria da cultura popular, permitir-se-á que os associados criem e visualizem situações que irão promover não só a geração de renda, do trabalho sob outros princípios, mas também reprodução do conhecimento que lá está presente como próprio, contribuindo assim para o processo emancipatório, além de promover um processo de retroalimentação das próprias universidades.

Ferrarini e Adams (2015, p. 214) reafirmam que a educação popular possui um compromisso com os sujeitos excluídos na sua luta cotidiana pela subsistência e, para realizá-lo, tem valorizado a dimensão produtiva da vida "reconhecendo o trabalho como via de libertação e autonomia". Isso permite uma realidade de convergência entre economia solidária e educação popular, ocorrendo um novo e peculiar espaço de potencialização do "trabalho como princípio educativo para vida e para a cidadania". Torres $(2013$, p. 27) considera necessária uma pedagogia para formar pensamento e subjetividades emancipadoras. Para o autor, o caráter emancipador 
da educação popular não consiste em divulgar conteúdos críticos, mas sim em "incorporar estratégias e critérios para a formação de pensamentos e subjetividades críticas e emancipadoras".

Entende-se aqui que o diálogo entre ideias se faz necessário, faz parte do processo de construção coletiva, lembrando que o conhecimento está nas universidades, mas também nas comunidades populares, inclusive podendo ser mais crítico que o conhecimento científico entendido, por muitos, como referência. Essas situações, que vêm sendo abordadas desde a introdução, serão observadas e problematizadas a partir dos dados buscados, pela presente pesquisa, junto aos integrantes.

\section{VIVÊNCIAS, CONTRAPONTOS E A CONSTRUÇÃO DO DIFERENTE: O MUNDO REAL E AS PROJEÇÕES NO PROCESSO DE INCUBAÇÃO}

Nesse momento, serão apresentadas as análises de algumas incubadoras e suas ações de incubação que darão visibilidade aos elementos pontuados anteriormente. De início, é realizada a caracterização da $\mathrm{IS}^{5}$, a qual é vinculada a uma universidade pública que tem como características a atuação interdisciplinar com a presença de docentes e bolsistas de diversas áreas do conhecimento, mas especialmente o compromisso ético-político de todos para com a economia solidária, o qual é "muito sério, muito forte", configurando-se como um envolvimento para além da bolsa de extensão, quase de militância, afirma o coordenador.

A IS2 também está vinculada a uma universidade federal. Na história de sua constituição, segundo seu coordenador, é possível identificar o interesse de servidores públicos na utilização do espaço universitário para a formação de trabalhadores jovens e adultos que sofriam com o analfabetismo, uma importante refração da questão social, pois estes eram pobres, desempregados e, na sua maioria, afrodescendentes que nunca ou pouco frequentaram os bancos escolares.

A IS3, por sua vez, é vinculada a um centro universitário de cunho comunitário. Entre as suas principais características, na atualidade, está o desenvolvimento de atividades seguindo três eixos específicos. O primeiro é a assessoria, "fomento aos grupos de economia solidária, formação, capacitação, prática, desenvolvimento desses sujeitos dentro dos empreendimentos". O segundo eixo é o político, envolvendo a discussão com os fóruns e movimentos sociais, as negociações dos grupos com a gestão pública ou com "clientes", entre outros fatores. O terceiro eixo é a linha da pesquisa, que inicialmente era precária, pois "se fazia muito e não se registrava isso em atividades científicas [...]".

A IS4 é vinculada a uma instituição privada de cunho público, portanto, comunitária. O objetivo da IS4 sempre foi criar novas tecnologias sociais para empreendimentos solidários. Essa era a metodologia, era uma inovação "a partir de Paulo Freire, com eles e não por eles, questões autogestionárias, mesmo existindo lideranças, que todos entendessem". Os alunos, "realizando adaptações, criando carrinhos", buscavam melhorar o desempenho as atividades dos catadores, possibilitando que muitos catadores saíssem da rua, contou a coordenadora da IS4.

A partir disso, foi possível identificar, durante a pesquisa, uma compreensão ampla das ISUs sobre incubação, envolvendo as dimensões ético-políticas, técnico-produtivas e econômicas, além dos aspectos educativos, formativos e de transformação dos sujeitos. A fala do coordenador da IS1 aponta que a incubação é um processo pedagógico de assessoramento socioeconômico que envolve três dimensões:

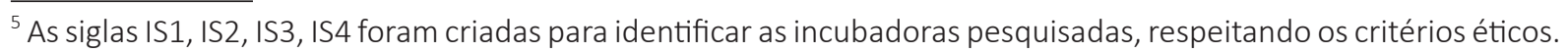


[...] dimensão ético política que está relacionada aos processos grupais, [...] dimensão técnicoprodutiva que está vinculada aos processos propriamente produtivos e de comercialização, [...], e uma dimensão econômica, propriamente dita, daria sentido, digamos assim, a respeito a viabilização econômica desses empreendimentos, talvez tivesse melhor colocado ai o seu processo de planejamento, de visibilização e de [...] constituição legal, de atendimento das normas tanto comerciais, quanto trabalhistas. (IS1)

Não diferente, a IS2 refere a incubação como uma assessoria técnico-educativa, sendo "[...] um processo de acompanhamento sistemático de EES", de cadeias produtivas, de feiras de economia solidária e outros arranjos "a partir de uma concepção de educação", evidenciando a educação popular como um dos caminhos norteadores. O entrevistado defende a educação, ou uma técnica educativa e formativa, que busca acompanhar de forma sistemática os grupos incubados, unindo-os, como também aponta a IS4 como "o saber acadêmico com o saber popular", construindo, de forma coletiva, conhecimento por meio da incubação e do trabalho coletivo.

A IS3, por sua vez, aprofunda esse entendimento e defende a incubação como um processo que deve contribuir para a transformação do sujeito. Nesse sentido, o entrevistado afirma:

[...] gente, precisa propor, estimular que as pessoas se reconheçam nos espaços onde elas estão, eu não vou dizer, fulano, você precisa usar EPI, se a pessoa nunca usou [...], quando a pessoa nunca usou uma luva no seu processo de trabalho, e vou chegar eu e falar pra mudar, como detentor do conhecimento e dizer que tem que usar, não pode se fazer isso. (IS3).

Para o entrevistado, é necessária uma mudança na concepção da pessoa sobre determinados processos, de modo que cada um compreenda a necessidade de mudança ou de adaptação e "se enxergue enquanto sujeito, para aos poucos mudar seu cotidiano e sua lógica [...]".

A metodologia de incubação utilizada - que pode variar em alguns momentos em função das especificidades dos EES, ISUs e IES - segue basicamente três etapas: pré-incubação, incubação e pós-incubação, como já mencionado. As ISUs 2, 3 e 4 afirmaram que discutem e seguem essa metodologia de incubação considerada tradicional.

Nessa realidade, as ISUs têm proporcionado formações utilizando-se de práticas pedagógicas que se preocupam com a adoção de metodologias participativas, atentando à compreensão dos envolvidos sobre os conceitos abordados nas oficinas, nas reuniões e/ou nas demais ações de incubação. Além disso, a formação toma por base, em suas linhas de atuação, os princípios teóricos e metodológicos que se assentam na educação popular e emancipatória, para que o trabalho desenvolvido possa tornar-se estratégia de resistência e de superação da dimensão capitalista, existindo a compreensão, por parte da equipe técnica, bem como dos associados, de que a formação/educação proposta deve utilizar-se dos conhecimentos já postos na comunidade, além de seguir e defender a perspectiva da transformação e emancipação socioeconômica dos envolvidos.

As ISUs, nesse contexto, protagonizam ações formativas aos trabalhadores, mas esses, talvez em dimensão ainda maior, têm formado ou retroalimentado acadêmicos e demais integrantes das ISUs e das IES. A IS1, por intermédio de seu coordenador, aponta que o trabalho realizado com grupos rurais é "realmente inspirador", pois, nesse espaço, realizam-se vivências dos bolsistas com os grupos. A IS1 destaca também que "os agricultores sabem muito mais de agroecologia do que os estudantes que vão lá trabalhar com eles", existindo assim uma "psicologia reversa". Afirma a entrevistada:

[...] é um termo da engenharia, a psicologia reversa, que nitidamente, nesse processo de interação dos bolsistas da área de ciências agrárias com os agricultores, os agricultores 
ensinam os bolsistas, eles estão lá fazendo o curso de agronomia e medicina veterinária e eles não sabem nada da realidade dos pequenos agricultores; isso é um pouco contrastado às vezes quando alguns dos meninos, quando um menino ou uma menina vem de uma família de pequenos agricultores, por exemplo, os meninos do MST que são bolsistas, eles tem uma capacidade, de aprendizado dessa relação muito superior, já os meninos e meninas que são de famílias urbanas que estão cursando agronomia ou veterinária, quando fazem a experiência de vivência e tomam contato com os grupos, é um choque de aprendizado [...]. (IS1).

Para o coordenador da IS1, a convivência entre os produtores agricultores com a universidade, essa que "dispõe de algumas ferramentas de percepção, de compreensão, de avaliação dos processos", permite uma interação, o que leva a um processo de aprendizado importante. 0 entrevistado ainda complementa que as ISUs estão se permitindo a compartilhar tecnologia com outros grupos e universidades, começando, de alguma forma, a multiplicar essas experiências que têm, no "intercâmbio" entre equipe técnica, produtores e consumidores, a materialização dos princípios e das ferramentas da educação popular, promovendo uma economia de formação recíproca.

A IS3, nesse mesmo sentido, reforça que o aprendizado de todos ocorre a partir do compartilhamento de conhecimentos, mencionando a importância da participação dos associados nas aulas da universidade. Para o coordenador, essa participação é simbolicamente um diferencial, "pois saem [os associados dos EES] das suas zonas de conforto, vão aos cursos, em turmas, explicando a sua prática de trabalho", configurando momentos de trocas de experiências em espaços considerados de "formação superior", e depois retornando para suas bases e contribuindo com o desenvolvimento local.

Porém é necessário mencionar que segue sendo um desafio para algumas ISUs e seus envolvidos aproximarem-se dos EES, em função da leitura de realidade, em alguns momentos oposta à já citada pela IS1. Isso se dá porque muitos associados ainda consideram as universidades um "nível superior" e, portanto, somente estas possuem a leitura adequada de realidade, ou seja, possuem o "saber supremo", "correto", não se introduzindo em nível de equidade no diálogo que está sendo estabelecido no processo de incubação.

Utiliza-se o entendimento de que a formação precisa fazer sentido aos associados e aos acadêmicos, pois, como destaca a IS2, na educação popular, o "aprendente vem com o que ele tem, com sua experiência de vida, mas que principalmente ele enxergue aquele conhecimento com algo que possa fazer sentido na sua vida e não ser meramente abstrato". Dessa forma, verifica-se que é necessário valorizar esses conhecimentos, pois a universidade, por mais que se esforce, pode não dar conta da formação ampliada e de promover as compreensões necessárias do mundo.

Destaca a IS1, para dar visibilidade a essa realidade, que as formações são "no sentido que ela aponta um conjunto de valores éticos políticos, anticapitalistas, antissistêmicos [...], da grande maioria dos consumidores da feira virtual. É possível ampliar e exemplificar essa perspectiva crítica utilizando-se da fala da IS4, a qual afirma que a formação emancipatória se dá em "determinados processos, com viés da mulher, quando vejo elas articuladas [...]", por exemplo, quando cooperativas foram estabelecidas, grupos autogestionários de massa falida foram criados e galpões de catadores foram organizados ao longo dos 30 anos de atuação da IES, diz a coordenadora.

A IS2, nesse mesmo sentido, afirma que as formações desenvolvidas pela ISU estão permitindo que o machismo possa ser desconstruído. Quanto à questão racial, embora os questionamentos ainda precisem ser aprofundados, eles têm sua importância pois visam enfraquecer o racismo interno e externo aos EES, às ISUs e às IES. Os questionamentos estão evitando a apatia das favelas por meio do fortalecimento dos movimentos sociais, e a defender a democracia. 
A emancipação, para o coordenador da IS3, é percebida "quando tu acompanhas meio distante e você vê os passos deles [...] e observa que o grupo se mantém, o empreendimento está se mantendo, não está entrando em crise, não está com dívidas e está se posicionando politicamente". Não se pode pensar, conforme diz o entrevistado, que está se desenvolvendo a autogestão, a qual implica resultados de emancipação, participação comunitária e valorização dos sujeitos, em formato de escada: "nunca é uma linha de ascensão, [...] é sempre em um movimento em espiral e, nesse momento em espiral, ora eu estou mais autogestionário, ora estou menos, ora estou mais emancipado, ora estou menos [...]".

Pontua-se, assim, que existem alguns desafios e até mesmo contradições nesse processo de promoção da emancipação humana, envolvendo percepções e questões socioeconômicas. Vive-se em um contexto no qual o capital predomina na orientação das relações sociais existentes, obrigando os trabalhadores, ou seja, os não detentores dos meios de produção, a criarem condições para a sua própria sobrevivência, sendo, por vezes, acompanhado pelas universidades, espaços que também é carregado de contradições.

\section{ALGUMAS CONCLUSÕES}

São inúmeros os desafios vivenciados pelas ISUs pesquisadas, as quais vêm proporcionando aos associados, por meio das formações e construções coletivas, condições para afastarem-se das refrações da questão social e dos processos de alienação. Desse modo, não somente é viabilizado o acesso a recursos financeiros, mas também a orientação em relação à reabertura de espaços de trabalho e novas possibilidades de organização, além do desenvolvimento de atividades educativas que permitem aos envolvidos observar a linha quase imperceptível entre aceitar a dimensão capitalista e se contrapor a ela.

Constatou-se, diante das análises, que as instituições de ensino superior (IES) pesquisadas foram e ainda são desafiadas nessa sociedade repleta de valores conservadores e elitistas que orientam os oligopólios "ávidos pelo lucro". Pode-se reafirmar e concluir, a partir das entrevistas, que as universidades têm se movido, nas últimas décadas, por caminhos baseados em um "solo movediço", enfrentando também as intempéries provocadas pela globalização econômica, pelo neoliberalismo, pelo capital especulativo financeiro, pelo conflito entre capital e trabalho e por crises na democracia. É esse o contexto que as IES são provocadas a afrontar, e vem enfrentando com ações de formação/qualificação de cunho crítico e emancipatório.

Para tal enfrentamento, as ISUs pesquisadas estão estimulando a construção de conhecimentos e caminhos que orientam as resoluções dos problemas sociais do mundo. Dessa forma, elas se constituem em um espaço no qual a ciência produzida, pelo menos em partes, direciona-se em favor da vida, buscando ampliar e qualificar a autonomia e a atitude dos envolvidos em suas ações e escolhas, promovendo, assim, a conscientização e emancipação social, política e econômica da comunidade em que está inserida.

\section{REFERÊNCIAS}

BARCELOS, E. S. A formação humana nos caminhos da promoção da vida cidadã. In. BARCELOS, E. S.; RASIA, P. C.; SILVA, E. W. (Org.). Economia solidária: sistematizando experiências. ljuí, RS: Editora Unijuí, 2010.

BARDIN, L. Análise de conteúdo. Lisboa: Edições 70, 2011.

INTERAÇÕES, Campo Grande, MS, v. 20, n. 2, p. 461-473, abr./jun. 2019 
BRASIL. Ministério da Educação (MEC). Decreto n. 5.773, de 9 de maio de 2006. Disponível em: http:// portal. mec.gov.br/component/content/article?id=116:qual-e-a-diferenca-entre-faculdades-centrosuniversitarios-e-. Acesso em: 14 set. 2016.

BRASIL. Lei n. 9.394, de 20 de dezembro de 1996. Estabelece as diretrizes e bases da educação nacional. Disponível em: http://www.planalto.gov.br/ccivil_03/leis//9394.htm

BRASIL. Constituição da República Federativa do Brasil de 1988. Disponível em: http://www.planalto.gov. br/ccivil_03/constituicao/constituicao.htm

COIMBRA, A. L. S.; SOUZA, M. B. Princípios e ações em economia solidária: a Intercoop/UFJF e o cooperativismo popular com egressos do sistema penitenciário de Juiz de Fora/MG. Proposta: Revista Trimestral de Debate da Fase, Rio de Janeiro, ano 31, n. 112, p. 4-15, 2007.

CULTI, M. N. Conhecimento e práxis: processo de incubação de empreendimentos econômicos solidários como processo educativo. Revista Otra Economia, São Leopoldo, RS, v. 3, n. 5, p. 146-65, 2009.

CULTI, M. N. Economia solidária: incubadoras universitárias e processo educativo. Proposta, Rio de Janeiro, v. 31, n. 111, p. 16-22, jan. 2007.

EID, F. Análise sobre processos de formação de incubadoras universitárias da Unitrabalho e metodologia de incubação de EES. In: PICANÇO, I.; TIRIBA, L. (Org.). Trabalho e educação. Aparecida, SP: Idéias \& Letras, 2004. p. 167-88.

FERRARINI, A. V.; ADAMS, T. A educação popular na formação de trabalhadores da economia solidária: avanços políticos e desafios pedagógicos. Ciências Sociais Unisinos, São Leopoldo, RS, v. 51, n. 2, p. 212 21, maio/ago. 2015.

FRAGA, L. S. Extensão e transferência de conhecimento: as incubadoras tecnológicas de cooperativas populares. 2012. 242 f. Tese (Doutorado em Política Científica e Tecnológica)- Universidade Estadual de Campinas (UNICAMP), Campinas, SP, 2012.

FRANTZ, W. Reflexões sobre universidade. In: ANDRADE, E.; ANDRIOLI, L. A.; FRANTZ, W. (Org.). Educação no contexto da globalização: reflexões a partir de diferentes olhares. ljuí, RS: Ed. Unijuí, 2013.

FRANTZ, W. Desafios à universidade no espaço das práticas sociais. In: BARCELOS, E. S.; RASIA, P. C.; SILVA, E. W. (Org.). Economia solidária: sistematizando experiências. Ijuí, RS: Editora Unijuí, 2010.

FREIRE, P. Cartas a Cristina. São Paulo: Paz e Terra, 2015.

GADOTTI, M. Trabalho e educação numa perspectiva emancipatória. In: FÓRUM MUNDIAL DE EDUCAÇÃO PROFISSIONAL E TECNOLÓGICA: Democratização, emancipação e sustentabilidade, 2., 2012, Florianópolis. Disponível em: https://sites.google.com/site/eticaesegurancadotrabalho/trabalho-e-educacao-numaperspectiva-emancipatoria

INSTITUTO DE TECNOLOGIA SOCIAL (ITS). Incubação de Cooperativas Populares e de Empreendimentos Econômicos Solidários. 2010. Disponível em: https://docs.wixstatic.com/ugd/85fd89_ deffb7e690e84956ad5a19c94be406b3.pdf. Acesso em: 6 nov. 2017.

MELO NETO, J. F. Educação Popular e "experiência". Contexto \& Educação, Ijuí, RS, ano 26, n. 85, p. 3150, jan./jun. 2011. 
MINAYO, M. C. S. Pesquisa social: teoria, método e criatividade. 33. ed. Petrópolis, RJ: Vozes, 2013.

MOURA, E. P. G. O que estamos fazendo quando incubamos? In: SCHOLZ, R. H. (Org.). Economia solidária e incubação: uma construção coletiva de saberes. São Leopoldo, RS: Oikos, 2014.

NOGUEIRA, M. D. P. Políticas de extensão universitária brasileira. Belo Horizonte: Editora UFMG, 2005.

OLIVEIRA, E. M. Incubadora de empreendimentos de economia solidária, territorialização e cooperação; elementos de uma educação sócio dialógica. In: CORDEIRO, A. M. R.; ALCOFORADO, J. L.; FERREIRA, A. G. (Org.). Territórios, comunidades educadoras e desenvolvimento sustentável. Coimbra, Portugal: Departamento de Geografia - Faculdade de Letras da Universidade de Coimbra, 2014.

PALUDO, C. Educação popular como resistência e emancipação humana. Cadernos CEDES, Campinas, SP, v. 35, n. 96, p. 219-38, maio/ago. 2015.

SANTOS, B. S. S. Educação Popular e Universidades. Palestra Proferida no Fórum da Educação Popular. Porto Alegre, 2016. Disponível em: https://www.youtube.com/watch?v=BW3p6nY-ASY. Acesso em: 15 jul. 2016.

SANTOS, A. M.; CRUZ, A. Incubadoras tecnológicas de cooperativas populares: interdisciplinaridade articulando ensino, pesquisa e extensão universitária. e-cadernos CES, n. 2, 2008. Disponível em: https:// journals.openedition.org/eces/1354

TORRES, A. A educação popular como prática emancipadora. In: STRECK, D. R.; ESTEBAN, M. T. (Org.). Educação popular: um lugar de construção social coletiva. Petrópolis, RJ: Vozes, 2013.

\section{Sobre os autores:}

Fabio Jardel Gaviraghi: Doutor em Educação das Ciências pelo Programa de Pós-Graduação em Educação nas Ciências peça Universidade Regional do Noroeste do Estado do Rio Grande do Sul (UNIJUÍ). Mestre em Serviço Social pelo Programa de Pós-Graduação em Serviço Social da Pontifícia Universidade Católica do Rio Grande do Sul (PUCRS). Docente do departamento de Serviço Social da Universidade Federal de Santa Maria (UFSM). Assistente Social. E-mail: fabiogaviraghi@yahoo.com.br, Orcid: http://orcid.org/0000-0002-6860-6274

Caroline Goerck: Doutora e Mestre em Serviço Social pelo Programa de Pós-Graduação em Serviço Social da Pontifícia Universidade Católica do Rio Grande do Sul (PUCRS). Docente do departamento de Serviço Social da Universidade Federal de Santa Maria (UFSM). Assistente Social. E-mail: carolinegoerck@yahoo.com.br, Orcid: http://orcid.org/0000-0002-4017-4289

Walter Frantz: Doutor em Ciências pela Universitat Munster, Alemanha. Professor do Programa de Pós-Graduação em Educação nas Ciências da Universidade Regional do Noroeste do Estado do Rio Grande do Sul (UNIJUI).E-mail: wfrantz@unijui.edu.br, Orcid: http://orcid.org/0000-0002-4528-7389 
